\title{
Clinical study of the oral manifestations and related factors in type 2 diabetics patients
}

\author{
Maria Goretti de Menezes Sousa ${ }^{1}$, Antonio de Lisboa Lopes Costa ${ }^{2}$, Angelo Giuseppe Roncalli
}

\section{Keywords:}

diabetes mellitus, epidemiology, mouth mucosa.

\begin{abstract}
D iabetes Mellitus (DM) is reported with and associated to oral alterations, with conflicting results. The aim of this study was to identify the prevalence of oral soft tissue alterations in type 2 diabetes mellitus patients.
\end{abstract}

Material and Methods: Socioeconomic variables, gender, heredity, capillary glucose control and local factors (prosthesis, dry mouth sensation) were analyzed in 196 diabetic and non-diabetic patients enrolled in HIPERDIA, at 41 Health Units of Natal, Brazil.

Study Design: A case study.

Results: The last blood glucose mean was $177.0 \mathrm{mg} / \mathrm{dl}$ for diabetics and $89.46 \mathrm{mg} / \mathrm{dl}$ for nondiabetics. Mean capillary blood glucose was elevated in diabetics $(215.95 \mathrm{mg} / \mathrm{dl})$; it was 102.31 $\mathrm{mg} / \mathrm{dl}$ in non-diabetics. The family history confirmed the heredity nature of the disease in $68.8 \%$ of diabetic patients $(n=66)(p<0.001)$; salivary flow was $49 \%(n=47)$ in diabetics, and $34 \%(n=$ $34)$ in non-diabetics. Candidiasis was present in $30.5 \%$ of diabetic patients $(n=29)$ and $36 \%$ of nondiabetics $(n=36)$. Both groups had lesions in the palate $-81.4 \%(n=35)$ in diabetics, and $71.1 \%$ in non-diabetics $(n=27)(p=0.68)$.

Conclusion: The alterations are not related to diabetes and are present independently of having or not type 2 Diabetes Mellitus.

\footnotetext{
${ }^{1}$ Master's degree student. State coordinator of oral health, Public Health Secretariat, RN state.

2 Doctoral degree in oral pathology. Associate professor II, UFRN.

${ }^{3}$ Doctoral degree in social dentistry. Associate professor I, UFRN. Paper submitted to the BJORL-SGP (Publishing Management System - Brazilian Journal of Otorhinolaryngology) on August 19, 2009 and accepted on December 15, 2010. cod. 6580
} 


\section{INTRODUCTION}

Diabetes mellitus (diabetes) is a complex metabolic disease characterized by altered carbohydrate, lipid, and protein metabolism, which results in marked or absolute insulin deficiency - type 1 diabetes - or peripheral tissue insulin resistance - type 2 diabetes. Type 3 is gestational diabetes, where there is carbohydrate intolerance during pregnancy. ${ }^{1}$

A Brazilian multicentre study on the prevalence of diabetes, coordinated by the Ministry o Health, ${ }^{2}$ has mapped the disease in this country: the prevalence is 7.6 $\%$ in the urban adult population of nine capitals. The study revealed that $46.5 \%$ of diabetics ignored their condition, and $22.3 \%$ had but did not treat the disease.

Faced with an increasing diabetic and hypertensive population, the Ministry of Health, in a partnership with State and Municipal Secretariats, scientific societies (diabetes, cardiology, and nephrology), and associations of diabetic and hypertensive patients, has reorganized healthcare through the Plan for Reorganizing Healthcare for Arterial Hypertension and Diabetes, to reduce the morbidity and mortality of these conditions. The plan improves healthcare for patients with these diseases by health-promoting actions involving preventive, curative and control measures. ${ }^{3}$

Several systemic diseases manifest in the mouth, including diabetes. Absence of metabolic control appears to alter the susceptibility of patients with diabetes to periodontal disease, fungal infections, and changes in taste. The relationship between diabetes and oral lichen planus and dental caries is less obvious; several studies have shown widely diverging results. ${ }^{4-7}$

A few studies have suggested that decrease salivary flow results from the use of certain drugs, which would result in changes within the mouth, leading to caries, periodontal disease, and soft tissue alterations; the latter may foster invasion by opportunistic microorganisms. Several types of drugs may cause a subjective feeling of dry mouth, or may induce low salivary flow; these include anticholinergics, antidepressants, diuretics, antihistamines, myorelaxants, diazepinic drugs, and sympatheticomimetics such as hypotensive drugs. ${ }^{8,9}$ This last category is commonly used by diabetics who also have arterial hypertension as a comorbidity.

On the other hand, there are published reports of salivary gland disorders as a systemic consequence of diabetes affecting the parenchyma of salivary glands, resulting in altered salivary gland function. Histological alterations in these glands change the shape and function of acinar cells, resulting in decreased enzyme activity because of degenerative complications of diabetic angiopathy, neuropathy, and hormone changes following metabolic derangement. ${ }^{10,11}$ Murrah $^{12}$ described the oral signs of diabetes as follows: xerostomy, angular cheilitis, decreased salivary flow, increased glucose levels in saliva produced by the parotid gland as a results of elevated blood glucose.

The scientific community has not reached any conclusion about the relation between use of dentures and oral alterations in diabetic patients. Several conflicting studies have been published on dentures as risk factors for stomatitis and candidiasis in diabetic ${ }^{13-15}$ and nondiabetic ${ }^{16,17}$ patients.

The purpose of this study was to check which oral soft tissue manifestations were found in type 2 diabetes, and the correlation between these findings and this complex disease.

\section{MATERIALS AND METHODS}

A observational individualized cross-sectional study was made from December 2007 to December 2008. The sample comprised 196 diabetic and non-diabetic patients. The sample size was calculated based on a $35 \%$ prevalence of outcomes (oral alterations), a $20 \%$ margin of error, and a $20 \%$ non-response rate. The confidence level was 95 $\%(\mathrm{a}=0.05){ }^{18}$

From an initial calculated sample of 220 patients, 10 $\%$ (20 persons) did not present, and $1.8 \%$ (4 persons) decided voluntarily not to participate. Thus, the final sample consisted of 196 patients, of which 96 were diabetic and 100 were non-diabetic.

The inclusion criteria were patients of both sexes aged 40 years or over, diagnosed with type 2 diabetes, and non-diabetics of both sexes and the same age group. The exclusion criteria were patients with type 1 diabetes and subjects aged less than 40 years.

A questionnaire was applied to gather data on the clinical history, the social and economic profile, ${ }^{19}$ and the dental history. A glucometer (Accucheck Roche) was used to measure glucose levels (capillary glucose), which was dichotomized as follows: postprandial values $\leq 140 \mathrm{mg} /$ $\mathrm{dL}$ - controlled glucose levels; and postprandial values $\geq$ $140 \mathrm{mg} / \mathrm{dL}$ - uncontrolled glucose levels. ${ }^{20,21}$ Arterial blood pressure was also measured. Two observers carried out the physical examination, which consisted of noting the status of the lips, the jugal mucosa, the tongue, the floor of the mouth, the hard and soft palates, and use of dentures. A World Health Organization (WHO) form for epidemiological studies was used. ${ }^{22}$ Diagnosis of different types of candidiasis was based on the clinical signs (Neville et al.). ${ }^{23}$ A similar procedure was adopted for the medical diagnosis of oral lichen planus, noting the presence of Wickham striae to characterize reticular lichen planus ${ }^{23}$ the clinical type encountered in the sample, as well as aphthous ulcers characterized by lesions covered with white-yellowish membranes surrounded by an erythematous halo. ${ }^{23} \mathrm{We}$ excluded non-pathologic or developmental alterations such as Fordyce granules, lingual varices, benign migratory glossitis, and fissured tongue. ${ }^{23}$ 
Our theoretical model used the health status of the oral mucosa as a dependent variable. Unaltered soft tissues in the mouth were considered normal, and altered soft tissues because of candidiasis, lichen planus, and aphtha were considered as an abnormal status.

Data analysis consisted of descriptive statistics of quantitative variables, the description of categorical variables based on the chi square test, and description of variables in the group of diabetic patients relative to the treatment. The statistical significance level was $5 \%$.

All participants were asked to sign a free informed consent form after being given detailed information about the goals of this study. The institutional review board approved the study (no. 044/05).

\section{RESULTS}

Descriptive statistics of quantitative variables showed that the age ranged from 40 to 81 years, the mean age of non-diabetic patients was 58.2 years, and of diabetic patients, 58.9 years. The mean time elapsed until diagnosis of diabetic patients was 9.1 years. The mean blood glucose level in non-diabetic patients was $89.4 \mathrm{mg} /$ $\mathrm{dL}$, and the mean blood glucose level in diabetic patients was $177 \mathrm{mg} / \mathrm{dL}$. The mean capillary blood glucose level in non-diabetic patients was $102.3 \mathrm{mg} / \mathrm{dL}$, and among diabetics, $215.9 \mathrm{mg} / \mathrm{dL}$. The mean arterial systolic pressure in non-diabetics was $126.9 \mathrm{mmHg}$, and among diabetics, $132 \mathrm{mmHg}$. The mean arterial diastolic pressure in nondiabetic patients was $81 \mathrm{mmHg}$, and in diabetic patients, $83.23 \mathrm{mmHg}$. (Table 1).

The non-diabetic patients comprised 100 subjects, of which 27 were male (27\%) and 73 were female (73 $\%)$; among the 96 diabetic patients, 31 were male $(32.3$ $\%)$ and 65 were female $(67.7 \%)$. In the non-diabetic study sample, 76 were black or brown (76.0 \%) and 24 were white $(24.0 \%)$; in the sample of diabetics, 70 were black or brown $(72.9 \%)$ and 26 were white $(72.9 \%)$. The social and economic status of non-diabetics included 28 subjects (28.0 \%) with higher income levels (classes A2, B1, B2, and C), and 72 (72.0\%) subjects with lower income levels (D and E). In diabetic patients, 26 subjects had higher income levels (27.1\%) and 70 subjects had lower income levels (72.9\%).

The family history of non-diabetics showed that there were 42 patients (42.0\%) with a history of diabetes in family members and 58 without any history of family members diagnosed with diabetes $(58.0 \%)$. The family history of diabetics showed that there were 66 patients (68.8\%) with a history of diabetes in family members and 30 without any history of family members diagnosed with diabetes $(31.2 \%)$, which was statistically significant $(p<0.001)$. There were 29 non-diabetic patients $(63.0 \%)$ in the relationship with parents category (degree of relationship with parents) and 17 (37.0\%) in the relationship with siblings category. There were 40 diabetic patients (59.7\%) in the relationship with parents category and 27 (40.3\%) in the relationship with siblings category.

The results of variables attributed to risk factors for the presence of arterial hypertension was that among non-diabetics there were 62 hypertensive patients $(62.0$ $\%)$ and 38 non-hypertensive patients (38.0\%). Among diabetics, there were 59 hypertensive patients (61.5\%) and 37 non-hypertensive patients (38.5\%).

The habit of smoking did not affect 76 non-diabetic patients (76.0 \%) who had not smoked for at least ten years, and therefore was considered a favorable effect, compared to 24 non-diabetic patients ( $24.0 \%)$ who smoked or had ceased smoking less than ten years ago, in whom it was considered an unfavorable effect. Among diabetic patients, these numbers were 74 (77.1\%) - favorable - and 22 (22.9 $\%)$ - unfavorable.

Decreased salivary flow was present in 34 nondiabetic patients (34.0\%); salivary flow was normal in 66 non-diabetic patients $(66.0 \%)$. Decreased salivary flow was present in 47 diabetic patients (49.0\%); salivary flow was normal in 49 diabetic patients (51.0\%).

Oral health (soft tissue examination) was normal in 58 non-diabetic patients ( $58.0 \%) ; 36$ non-diabetic patients (36.0\%) had candidiasis (palatal prosthetic stomatitis and commissural angular cheilitis), and 6 non-diabetic patients (6.0\%) had other conditions (lichen planus and aphtha). Oral health was normal in 61 diabetic patients (64.2\%); 29 diabetic patients $(30.5 \%$ ) had candidiasis (palatal prosthetic stomatitis and commissural angular cheilitis), and 6 diabetic patients (5.3\%) had other conditions (lichen planus and aphtha).

The site of oral conditions in non-diabetic patients was the hard palate in 35 patients (81.4\%), the jugal mucosa in 4 patients $(9.4 \%)$, and other sites in another 4 patients $(9.4 \%)$. The site of oral conditions in diabetic patients was the hard palate in 27 patients (71.1\%), the jugal mucosa in 2 patients $(5.8 \%)$, and other sites in 8 patients (23.1\%).

Full upper dentures were used by 52 non-diabetic patients (52.0\%); 48 non-diabetic patients ( $48.0 \%$ ) did not use full dentures or used other types of dental prosthetic appliances. Full upper dentures were used by 50 diabetic patients (52.1\%); 46 diabetic patients did not use full upper dentures or used other types of dental prosthetic appliances (47.9\%).

In 52 non-diabetic patients that used dentures, 36 had candidiasis (36\%). In 50 diabetic patients that used dentures (52.1\%), 29 had candidiasis (30.5).

There were 20 non-diabetic patients $(20.0 \%)$ that used complete lower dentures; 80 non-diabetics did not use dental prosthetic appliances (80.0\%). There were 18 diabetic patients (18.8\%) with full lower dentures; 78 diabetics did not use dental prosthetic appliances (81.2 \%) (Table 2). 
Table 1. Descriptive statistics of quantitative variables in the study sample (2009).

\begin{tabular}{cccccccccc}
\hline Variable & Group & $\mathrm{n}$ & Mean & S.D. & Min & Q25 & Med & Q75 & Max \\
\hline \multirow{4}{*}{ Age } & Non-diabetics & 100 & 58.29 & 10.19 & 31 & 51 & 60.50 & 65 & 80 \\
& Diabetics & 96 & 58.94 & 10.29 & 36 & 52 & 60.00 & 66 & 81 \\
& Total & 196 & 58.61 & 10.22 & 31 & 51 & 60.00 & 65 & 81 \\
Time before & Non-diabetics & - & - & - & - & - & - & - & - \\
diagnosis & Diabetics & 96 & 9.16 & 8.28 & 0 & 3 & 7.00 & 14 & 47 \\
& Total & 96 & 9.16 & 8.28 & 0 & 3 & 7.00 & 14 & 47 \\
Last blood glucose & Non-diabetics & 13 & 89.46 & 17.09 & 55.00 & 79.50 & 92.00 & 98.00 & 120 \\
& Diabetics & 93 & 177.06 & 82.52 & 70.00 & 117.00 & 146.00 & 219.50 & 443 \\
& Total & 106 & 166.32 & 82.66 & 55.00 & 106.75 & 137.00 & 209.25 & 443 \\
Capillary glucose & Non-diabetics & 100 & 102.31 & 19.69 & 70.00 & 90.00 & 100.00 & 112.00 & 215 \\
& Diabetics & 96 & 215.95 & 103.44 & 67.00 & 129.00 & 193.00 & 292.25 & 497 \\
& Total & 196 & 157.97 & 93.02 & 67.00 & 96.00 & 115.00 & 193.50 & 497 \\
Systolic A.P. & Non-diabetics & 100 & 126.90 & 18.52 & 80 & 120 & 120.00 & 140 & 180 \\
& Diabetics & 96 & 132.08 & 20.62 & 90 & 120 & 130.00 & 140 & 200 \\
& Total & 196 & 129.44 & 19.69 & 80 & 120 & 130.00 & 140 & 200 \\
Diastolic A.P. & Non-diabetics & 100 & 81.00 & 12.59 & 50 & 70 & 80.00 & 90 & 120 \\
& Diabetics & 96 & 83.23 & 14.20 & 50 & 80 & 80.00 & 90 & 140 \\
& Total & 196 & 82.09 & 13.41 & 50 & 73 & 80.00 & 90 & 140 \\
\hline
\end{tabular}

Analysis of diabetics and type of treatment showed that in diabetic patients aged 60 years or less 37 diabetic patients $(72.5 \%)$ were monitored monthly, and 14 diabetic patients $(27.5 \%)$ were not monitored monthly. There were 30 diabetics (66.7\%) aged over 60 years that were monitored monthly; 15 diabetics (33.3\%) were not monitored monthly.

In the group aged 60 years or less, only 12 patients (23.5\%) used insulin; 39 patients (76.5\%) were not using insulin. In the group aged over 60 years, 8 patients (17.8\%) were using insulin, and $37(82.2 \%)$ were not using insulin.

There were 40 patients (78.4\%) taking oral hypoglycemic drugs in the group aged 60 years or less; 11 patients in this group (21.6\%) were not taking hypoglycemic medication. In the group aged over 60 years, 39 (86.7\%) were taking oral hypoglycemic drugs, and only 6 patients $(13.3 \%)$ were not taking hypoglycemic medication.

In the group aged 60 years or less, 34 patients (66.7 $\%)$ were on diets, while 17 patients (33.3\%) did not follow any diet. In the group aged over 60 years, 38 patients (84.4\%) were on diets, while 7 patients (15.6\%) did not follow any diet (Table 3).

\section{DISCUSSION}

Several systemic conditions cause well defined effects in the mouth; many of these alterations are pathognomonic of the main disease, and have been well studied. In other diseases, such as diabetes, the relation with oral manifestations of the disease remains controversial.

The two study sample groups (diabetics and nondiabetics) did not differ statistically relative to age, sex, skin color, and income level, which characterized type 2 diabetes as being independent of the social and demographic status of the general population; the disease is present in all social classes. ${ }^{2,24,25}$

The mean capillary glucose level was high (215.9 $\mathrm{mg} / \mathrm{dL}$ ), even with many patients using oral hypoglycemic drugs and insulin. It is interesting to note that irrespective of positive answers for monthly monitoring at basic healthcare units and following diets, patients were unable to attain adequate control of blood glucose levels; thus, more effective action is required. Furthermore, there are known difficulties in managing blood glucose levels in diabetics because of the complex nature of this disease.

The aim of management is to effectively control the disease in such individuals; ${ }^{26}$ if uncontrolled, diabetes causes systemic complications because of long-term hyperglycemia. Our results relative to blood glucose levels in diabetic patients concur with those of Guggenheimer, ${ }^{15}$ Manfredi ${ }^{7}$ and Carvalho. ${ }^{27}$ According to the American Diabetes Association, ${ }^{28}$ controlling blood glucose is essential for managing diabetes; such control is associated with a reduced rate of several systemic complications.

In our study sample, diabetic patients and nondiabetics could present arterial hypertension or not. The results showing control of arterial systolic and diastolic pressure to normal limits were distributed homogeneously 
Table 2. Description of categorical variables in the study sample (2009).

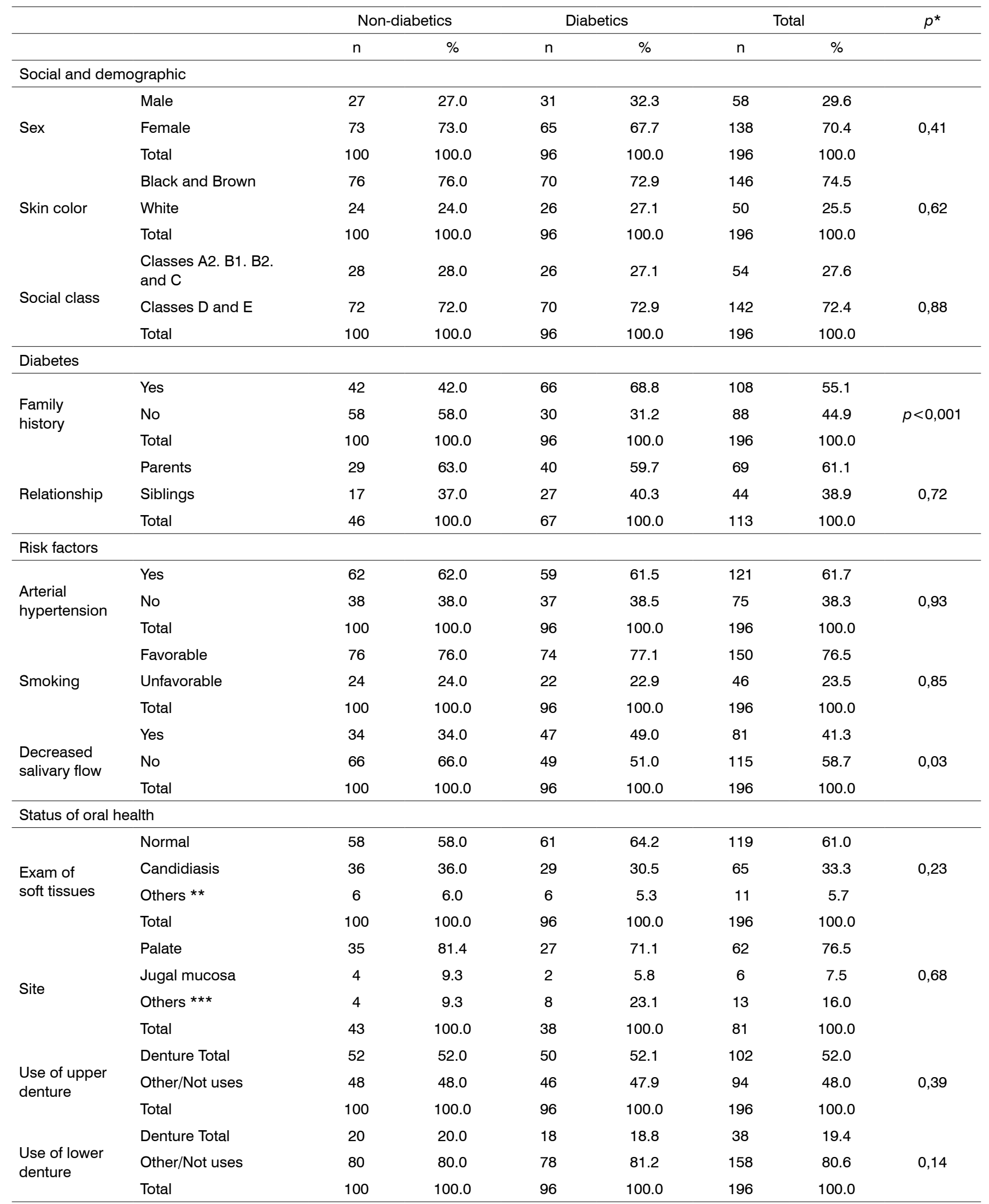

* Based on the chi square test; ** Lichen planus and aphtha; ***Labial commissure, tongue, and alveolar/gingival margins 
Table 3. Description of treatment variables in the group of diabetics (2009)

\begin{tabular}{|c|c|c|c|c|c|c|c|c|}
\hline & & \multicolumn{2}{|c|}{$\leq 60$ years } & \multicolumn{2}{|c|}{$>60$ years } & \multicolumn{2}{|c|}{ Total } & \multirow[t]{2}{*}{$p^{*}$} \\
\hline & & $n$ & $\%$ & $\mathrm{n}$ & $\%$ & $\mathrm{n}$ & $\%$ & \\
\hline \multirow{2}{*}{$\begin{array}{l}\text { Monthly } \\
\text { monitoring }\end{array}$} & Yes & 37 & 72.5 & 30 & 66.7 & 67 & 69.8 & \multirow{2}{*}{0.53} \\
\hline & Total & 51 & 100.0 & 45 & 100.0 & 96 & 100.0 & \\
\hline \multirow{2}{*}{ Use of insulin } & Yes & 12 & 23.5 & 8 & 17.8 & 20 & 20.8 & \multirow{2}{*}{0.48} \\
\hline & Total & 51 & 100.0 & 45 & 100.0 & 96 & 100.0 & \\
\hline \multirow{3}{*}{$\begin{array}{c}\text { Use of } \\
\text { hypoglycemic } \\
\text { drugs }\end{array}$} & Yes & 40 & 78.4 & 39 & 86.7 & 79 & 82.3 & \multirow{3}{*}{0.29} \\
\hline & No & 11 & 21.6 & 6 & 13.3 & 17 & 17.7 & \\
\hline & Total & 51 & 100.0 & 45 & 100.0 & 96 & 100.0 & \\
\hline Use of diet & Yes & 34 & 66.7 & 38 & 84.4 & 72 & 75.0 & 0.45 \\
\hline
\end{tabular}

in both groups. Diabetes is an independent risk factor for microvascular disease; it is commonly associated with elevated arterial pressure. Thus, controlling blood glucose helps avoid complications of diabetes in the mouth, ${ }^{10,13,14,24}$ cardiovascular diseases, retinopathy, and nephropathy. ${ }^{28}$

The literature shows that the family history of diabetics has been widely studied to find inheritance patterns in this disease, around which researchers agree. We found a positive association for a family history of diabetes: 66 patients (68.8\%) had diabetic family members, mostly parents (father or mother). These findings are similar to those of Goldenberg, ${ }^{25}$ Crispim $^{29}$ and Goldenberg. ${ }^{30}$

Smoking in our sample included a 'favorable' category (patients who had stopped smoking for more than 10 years). This variable was positive in interviewees that confirmed cessation of smoking in this sample of adult and elderly subjects. Smoking has been related to vascular complications in diabetic and hypertensive patients; encouraging cessation of smoking is one of the measures for these groups, although the consequences of smoking are similar to those in the general population. ${ }^{29}$

Studies on salivary flow have shown conflicting results because of the different methods that have been used - measurements of saliva at rest, stimulated salivary flow, self-reported decreased salivary flow in diabetics and non-diabetics. We found more diabetic patients with decreased salivary flow compared to non-diabetic patients. Altered salivary flow in diabetic patients has been attributed to changes in the parenchyma of salivary glands ${ }^{12}$ and to complications of the disease - neuropathy and angiopathy. ${ }^{10,11}$ Quirino et al. ${ }^{14}$ reported different results in an analysis of diabetic patients with controlled and uncontrolled blood glucose levels; they reported that decreased salivary flow was present in the uncontrolled group. Chávez et al. ${ }^{10}$ found no statistical significance in salivary flow patterns between well-controlled diabetic patients and a control group of non-diabetics.

Features of healthy soft tissues were present in diabetics and non-diabetics. We found no association between candidiasis and type 2 diabetes in our sample; it was equally present in both groups. We suggest that there is a need for a better definition of the host-parasite relationship. Oral candidiasis has been related to several factors, including diabetes. These factors, as mentioned in the literature, include decreased salivary flow in diabetic patients because of altered salivary glands, ${ }^{12}$ altered glucose levels in saliva that could facilitate adhesion of C. albicans to oral tissues, ${ }^{31,30}$ uncontrolled blood glucose levels, ${ }^{30}$ and use of dentures or poorly fitting dental appliances; ${ }^{15,16,32,24}$ these factors would not act in isolation, but rather as a set of risk factors. ${ }^{14,31,33}$

The palate is the most frequent site of these changes in both groups; it appears to be related more strongly with the presence of full upper dentures ${ }^{13,24}$ as a possible predisposing factor for candidiasis. This infection was present in diabetic and non-diabetic subjects. The area under the dentures would be more susceptible to fungal infection because of poor host defense due to lack of salivary factors. ${ }^{16}$ The microorganisms would form a biofilm that facilitates adhesion, as a first step for fungal infection. ${ }^{32}$ Angular cheilitis was directly related with the type and time of use of dentures - lack of adequate vertical dimension and quality of dentures.

Our results are similar to those of Quirino et al. ${ }^{14}$ and Shulman et al. ${ }^{16}$ The latter, in a study of risk factors for denture-associated stomatitis and candidiasis of 3,450 adults, found no association between diabetes and changes in soft tissues of the mouth because of full dentures. De 
Lima et al. ${ }^{17}$ compared the denture-associated oral manifestations in diabetic and non-diabetic patients and found more oral lesions in non-diabetic patients.

Concerning the treatment variables, monthly followup at healthcare units consists of delivering medication and assessing the health status in general, including measuring arterial blood pressure, checking blood glucose levels, and identifying patients not responding to the prescribed regimen; these patients are monitored for more effective control. ${ }^{26}$

We found that adhesion to outpatient care at basic healthcare units - in which the Family Health Program is conducted - was significant in both groups. Monthly visits include discussing healthcare measures for diabetes and high blood pressure, although blood glucose levels are not monitored at these units, which lack glucometers. Return visits depend on physicians.

The variables on insulin and hypoglycemic medication showed that the treatment of choice for diabetics was oral hypoglycemic drugs, to which diet was added for controlling the disease in both groups. Nevertheless, we found that capillary glucose levels were elevated in diabetic patients; this suggested the need for reassessing the prescribed treatment and stimulating more rigorous diets and exercise. ${ }^{28,34}$ Appropriate medication - sulphonylureas, biguanide, or insulin - as needed for controlling glucose levels in these patients. ${ }^{34}$

\section{CONCLUSION}

The findings of this study were unrelated to the presence or absence of type 2 diabetes; there are several factors that may give rise to these changes in the oral cavity, one of them being the use of dental prosthetic appliances.

\section{REFERENCES}

1. Vernillo, AT. Diabetes mellitus: relevance to dental treatment. Oral Surg Oral Med Oral Pathol Oral Radiol Endod.2001;91:263-70.

2. Estudo multicêntrico sobre a prevalência do diabetes mellitus no Brasil. Brasília- Ministério da Saúde - 1991.

3. Barbosa RB, Barceló A, Machado CA. National campaign to detect suspected diabetes cases in Brazil: a preliminary report. Rev Panam Salud Publica.2001;10:324-7.

4. Lundström. I. M. C. Incidence of diabetes mellitus in patients with oral lichen planus. Int J Oral Surg.1983;12:147-52.

5. Albrechet M, Bánóczyj de, Tamás GYJr. Ocorrence of oral leukoplakia and lichen planus in diabetes mellitus. J Oral Pathol Med.1992;21:3646.

6. Petrou-Amerikanou C, Markopoulos K, Belazi M, Karamitsos D, Papanayatou $\mathrm{P}$. Prevalence of oral liquen planus in diabetes mellitus according to the type of diabetes. Oral Dis.1998;4:37-40.

7. Manfredi M, Mccullough MJ, Vescovi P, Al-Kaarawi ZM, Porter SR. Update on diabetes mellitus and related on oral diseases. Oral Dis. 2004; 10:187-200

8. Scully CCBE. Drug effects on salivary glands: dry mouth. Salivary glands and saliva. Oral Dis.2003;9:165-76.
9. Schifter M. Oral and dental manifestations of xerostomia: public health implications of a common and under-recognized adverse drug reaction. NSW Public Health Bulletin.1999;10:17-8.

10. Chavez EM, Taylor GW, Barrel LN, Ship J. Salivary function and glycemic control in older persons with diabetes. Oral Surg Oral Med Oral Pathol Oral Radiol Endod.2000;89(3):305-11.

11. Carboni AMG, Carvalho LAC, Mello WR, Magalhães MHCG. Anomalias sistêmicas e bucais em pacientes com diabetes mellitus: revisão e caso clínico. Diabetes Clínica.2000;4:62-68.

12. Murrah VA, Crosson JT, Sauk JJ. Patótid gland basement membrane variation in diabetes mellitus. J Oral Pathol.1985;14:236-46.

13. Hill LVH, Tan MH, Pereira LH, Embil JA. Association of oral candidiasis with diabetic control. J Clin Pathol.1989;42:502-5.

14. Quirino MRS, Birman EG, Paula CR, Gambale W, Corrêa B, Souza VM. Distribution of oral yeasts in controlled and uncontrolled diabetic patients. Rev Microbiol.1994;25:37-41.

15. Guggenheimer J, Moore PA, Rossie K, Myers D, Mongelluzzo MB, Block HM, et al. Insulin-dependent diabetes mellitus and oral soft tissue pathologies II. Oral Surg Oral Med Oral Pathol Oral Radiol Endod.2000;89:570-6.

16. Shulman J D, River-Hidalgo F, Beach M M. Risk factors associated with denture stomatitis in the United States. J Oral Pathol Med. 2005;34:340-6.

17. De Lima D C, Nakata G C, Balducci I, Almeida JD. Oral manifestations of diabetes mellitus in complete denture wearers. J Prosthet Dent. 2008;99:60-5.

18. Medronho RA. Epidemiologia. Ed. Atheneu; 2004.

19. Almeida, Pergentino M. \& Wickerhauser, Hilda. O critério ABA/ ABIPEME - em busca de uma solução. Um estudo e uma proposta submetidos à ABA - Associação Brasileira de Anunciantes e ABIPEME - Editora da Associação Brasileira dos Institutos de Pesquisa de Mercado. São Paulo, Abril a Junho, 1991.

20. Gross JL, Silveiro SP, Camargo JL, Reichelt AJ, Azevedo MJ. Diabetes Melito: diagnóstico, classificação e avaliação do controle glicêmico. Arq Bras Endocrinol Metab.2002;46:16-26.

21. Sartori MS, Aragon FF, Padovani CR, Pimenta WP. Contribution of post-breakfast plasma glucose to the glycemic control of type 2 diabetic patients. Arq Bras Endocrinol Metab.2006;50:53-9.

22. WHO-Oral health surveys, basic methods. 4. ed. Geneva: World Health Organization 1997.

23. Neville BW, Damm DD, Allen CM, Bouquot JE. Patologia Oral \& Maxilofacial. Ed. Guanabara Koogan; 2004.

24. Dorocka-Bobkowska B, Budtz-Jorgensen E, Wloch, S. Non-insulindependent diabetes mellitus as a risk factor for denture stomatitis. J Oral Pathol Med.1996;25:411-5.

25. Goldenberg P, Schenkman S, Franco LJ. Prevalência de diabetes mellitus: diferenças de gênero e igualdade entre os sexos. Rev Bras Epidemiol.2003;6(1):18-28.

26. Assunção MCF, Santos IS \& Costa JSD. Avaliação do processo da atenção médica: adequação do tratamento de pacientes com diabetes mellitus, Pelotas, Rio Grande do Sul, Brasil. Cad Saúde Pública. 2003;18(1):205-11.

27. Carvalho LAC, Carboni AMG, Melo WR, Magalhães MHCG, Antunes, JLF. Pacientes portadores de diabetes tipo 2: manifestações sistêmicas e orais de interesse para o atendimento odontológico. RPG Rev Pós Grad.2003;10:53-8.

28. American Diabetes Association. Standards of medical of medical care for patients with diabetes mellitus. - Position Statement. Diabetes Care.2003;26:533-50.

29. Crispim D, Canani LH, Gross JL, Tschiedel B, Souto KEO, Roisenberg I. Familial history of type 2 diabetes in patients from southern Brazil and its influence on the clinical characteristics of disease. Arq Bras Endicrinol Metab.2006;50(5):862-8.

30. Goldenberg P, Franco LJ, Pagliaro H, Silva RS, Santos CA. Diabetes mellitus auto-referido no município de São Paulo: prevalência e desigualdade. Cad Saúde Pública.1996;12(1):37-45. 
31. Darwazeh AMG, Macfarlane TW, Mccuish A, Lamey PJ. Mixed salivary glucose levels and candidal carriage in patients with diabetes mellitus. J Oral Pathol Med.1991;20:280-3.

32. Soysa NS, Samaranayake LP, Ellepola ANB. Diabetes mellitus as a contributory factor in oral candidosis; Diabet Med.2006;23(5):455-9.
33. Willis AM, Coulter WA, Fulton CR, Hayes JR, Bell PM, Lamey PJ. Oral Candida Carriage and Infection in Insulin-treated Diabetic Patients. Diabetic Medicine 16:675-9, British Diabetic Association, 1999.

34. ALAD (Associação Latino-Americana de diabetes), 2000. Guias ALAD 2000. Para El Diagnostico y Manejo de La Diabetes Mellitus Tipo 2 Com Medicina Baseada em Evidencia. 28 outubro 2000. 